\title{
A clinical trial gone awry: the Chocolate Happiness Undergoing More Pleasantness (CHUMP) study
}

\begin{abstract}
The randomized controlled trial is the "gold standard" for evaluating the benefits and harms of interventions. The Chocolate Happiness Undergoing More Pleasantness (CHUMP) study was designed to compare the effects of dark chocolate, milk chocolate and normal chocolate consumption on happiness. Although the intention-to-treat analysis showed that participants who received either dark or milk chocolate were happier than those who received no additional chocolate, the actual-consumption analysis showed that there were no differences between any of the groups. The reason for this result is that many participants switched groups mid-study because of their personal chocolate preferences. Although the CHUMP study was pleasurable, it demonstrated the difficulties associated with performing a truly blinded clinical trial.
\end{abstract}

$\mathrm{T}$ he randomized controlled trial is the "gold standard" for testing the beneficial and harmful effects of interventions. There has been a growing concern in the literature about the potential for bias during randomization of participants in clinical trials. ${ }^{1-5} \mathrm{I}$ designed the Chocolate Happiness Undergoing More Pleasantness (CHUMP) study to compare the effects of dark chocolate, milk chocolate and "normal" chocolate consumption on happiness. The CHUMP study was a double-blinded clinical trial, and it demonstrated the difficulties associated with performing a truly blinded clinical trial.

\section{Methods}

The CHUMP study was conducted over a I-month period at a tertiary pediatric health care centre. Between Oct. 15, 2006, and Nov. 15, 2006, I44 adults were asked to participate in the CHUMP study. Owing to the study's popularity and the insistence of the research ethics board, an additional 36 adults were added to the study, for a total of I80 participants (Io8 women, 72 men).The research ethics board of the Chocolate Consumption Society approved the CHUMP study.

The participants were randomized into 3 study groups. Group I received I dark chocolate bar (50 g, > 90\% cocoa) each day, and group 2 received I milk chocolate bar $(50 \mathrm{~g}$, $20 \%$ cocoa) each day. Members of group 3 did not receive any additional chocolate; however, they continued with their normal chocolate-eating habits.

Each participant rated their happiness before and after the study using a visual analog scale (o = unhappy, Io = happy). Participants were also asked to rate their health, global happiness and personal work history ( $0=$ worst, $\mathrm{Io}=$ best). In order to establish participants' baseline chocolate-eating

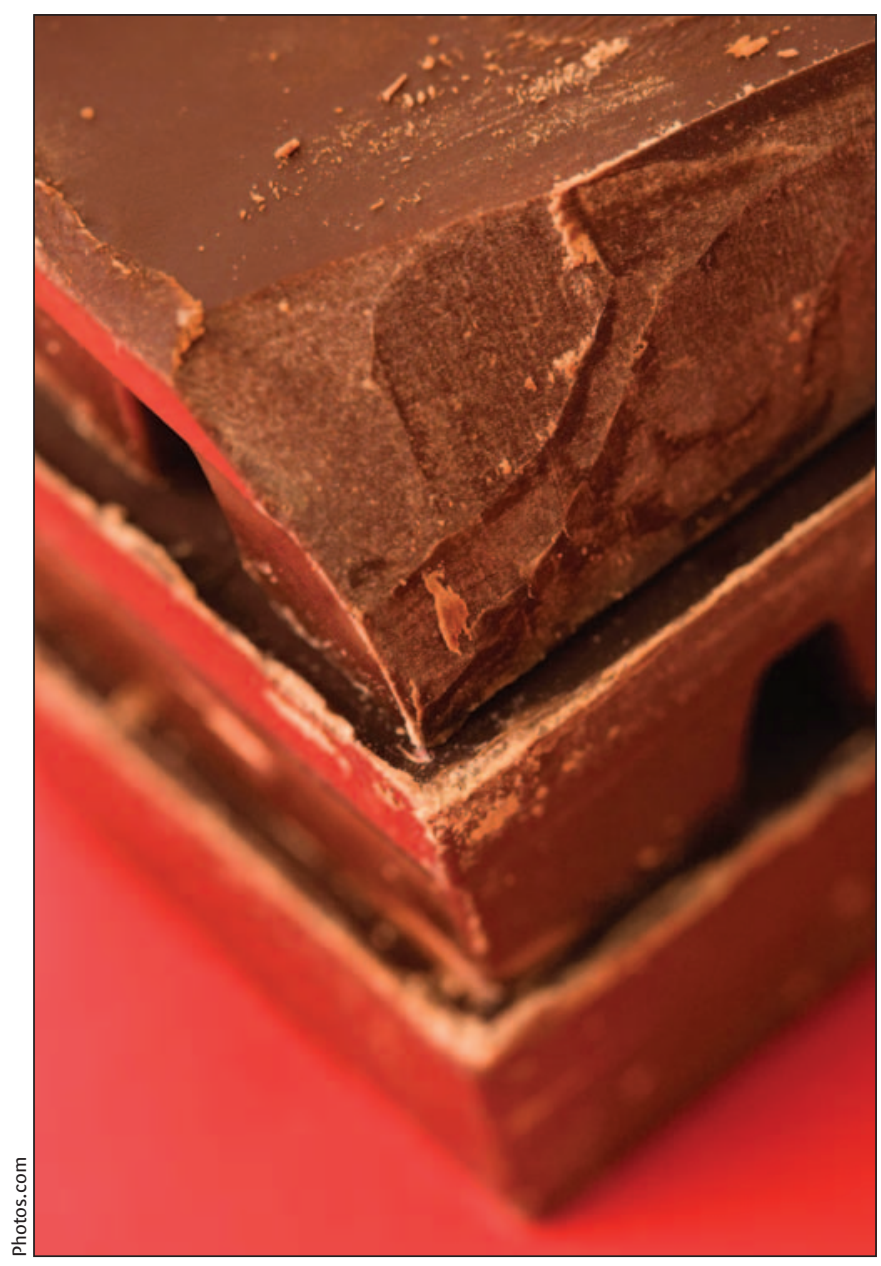

habits, participants were asked the frequency of chocolate consumption and the amount consumed on a daily basis to give a total chocolate bar day-equivalent. The total chocolate bar day-equivalent included both dark chocolate bar dayequivalents and milk chocolate bar day-equivalents.

I anaylzed contingency tables with $\chi^{2}$ tests, and I used analysis of variance to test for differences in the mean chocolate consumption among the 3 groups. No specific research funding was obtained for the CHUMP study; however, Costco provided a generous discount toward the purchase of the boxes of chocolate consumed in the study.

\section{Results}

The CHUMP study began with 6o participants in each group. Despite my efforts to keep the study groups blinded, some of the participants changed groups mid-study. Indeed, those in the control group (who received no extra chocolate) decided to start 
raiding the chocolate of those in the interventional arms (dark chocolate or milk chocolate). Furthermore, participants in the dark and milk chocolate groups traded chocolate based on their individual preferences. The milk chocolate study group was the most popular, as the number of participants in this group increased from 60 at inception to 82 at completion.

Table I shows the characteristics of the study participants at the beginning of the study. There was no significant difference in age or in the chocolate consumption habits of people in the dark chocolate, milk chocolate or no chocolate groups.

Another problem that occurred during the study was the holiday known as Halloween. Participants' chocolate consumption changed following Halloween, as some participants increased their chocolate consumption by eating extra chocolate that was intended to be distributed to children on Halloween and by raiding their children's loot bags for extra treats.

In the post-study survey, I attempted to identify any changes in the participants' eating preferences. The intention-to-treat analysis (6o participants per group) and the "actual-consumption" analysis are presented in Table 2. The actual-consumption analysis was performed after adjustment for those participants who changed study groups mid-study. As shown in Table 2, the intention-to-treat analysis predicted that participants in either "intervention" arm were more likely to be happy than those in the control arm. However, after the actual-consumption analysis was performed, there is no significant difference in happiness between any of the groups.

\section{Interpretation}

The strong belief that chocolate consumption leads to more happiness was not observed in the CHUMP study. A far more important indicator of happiness appears to be "getting what you want, when you want it." As shown by the intention-totreat analysis in Table 2, participants in the dark chocolate or milk chocolate intervention groups were far more likely to be happy. However, once the participants who had changed groups during the course of the study were accounted for, there was no significant difference in happiness among the 3 groups. This suggests that people who were most unhappy with the "no chocolate" intervention were more likely to switch to the dark or milk chocolate groups.

There are several limitations of the CHUMP study. One participant noted in the post-study interview: "My selection into the 'no chocolate' group led to utter disappointment, and I made an all-out attempt to get at least a few chocolate bars for free." Thus, participant randomization and subsequent recognition of being in the "no chocolate" group may

Table 1: Characteristics of participants in the CHUMP study

\begin{tabular}{|c|c|c|c|c|}
\hline Characteristic & \multicolumn{3}{|c|}{ Study group; mean $(S D)^{*}$} & $p$ value \\
\hline Patient age & $38.4(9.8)$ & $40.2(10.2)$ & 37.4 (10.4) & 0.37 \\
\hline Female, no. (\%) & $36(60.0)$ & $36(60.0)$ & $36(60.0)$ & \\
\hline Dark chocolate bar-days & $0.07(0.04)$ & $0.10(0.06)$ & $0.11(0.08)$ & 0.42 \\
\hline Total chocolate bar-days & $0.41(0.08)$ & $0.41(0.11)$ & $0.48(0.11)$ & 0.54 \\
\hline
\end{tabular}

*Unless otherwise specified.

Table 2: Intention-to-treat and actual-consumption analysis for CHUMP study participants' self-rated happiness with various aspects of their lives

Study group; change in happiness (post-study minus pre-study happiness) (SD)

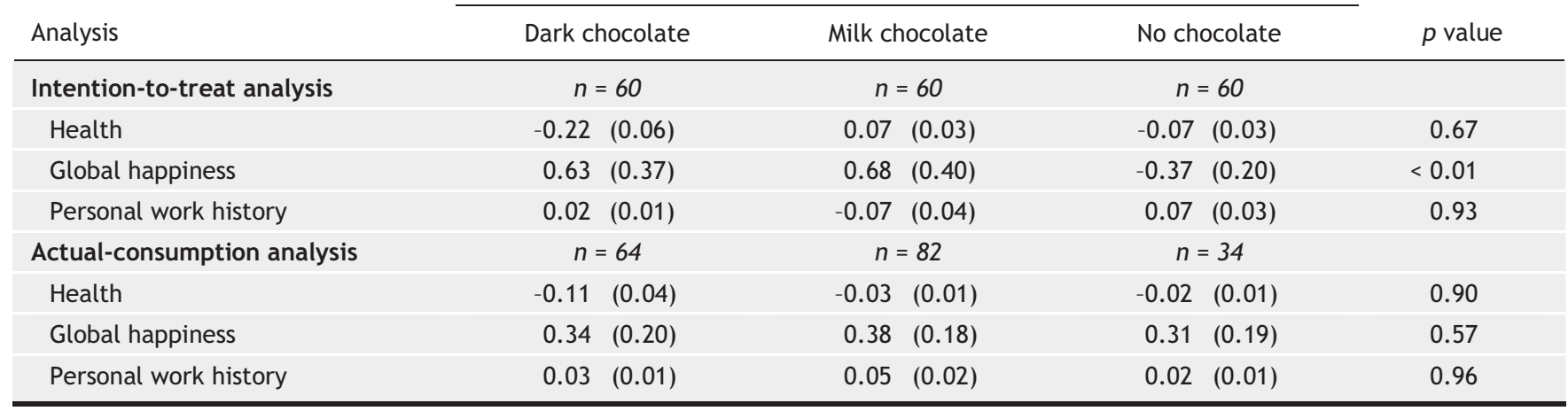


have adversely affected the happiness measures.

Second, the fact that the study period overlapped with Halloween may have adversely affected the overall consumption of chocolate during the study, and this may have led to crossover contamination.

Third, I made no attempt to control for other possible sources of happiness, such as the other basic "Cs" of happiness: candy, chips, cookies, caffeine and cola. Although consumption of any of these Cs would have led to happier participants, it may have had additive or multiplicitative effects with chocolate consumption leading to biased results.

In conclusion, the CHUMP study shows the pitfalls of running a clinical trial in I locale. Crossover and contamination of the study groups are easily achieved when taste buds are involved. However, despite the problems of running a clinical trial, there is one advantage: the author has a year's supply of chocolate left in his basement. Ah, happiness!

\section{Kevin Chan MD MPH}

Pediatric emergency physician

Toronto, Ont.
Competing interests: There are no conflicts to report. However, if any chocolate company feels induced to supply me with a lifetime supply of dark chocolate, I would hardly refuse.

Acknowledgements: I greatly appreciate the low prices at Costco that allowed for the cheap purchase of chocolate used in this study.

Disclaimer: For anyone who takes these data and analyses seriously, I also have some Florida swampland for sale.

\section{REFERENCES}

I. Van Der Windt DAWM, Koes BW, Aarst MV, et al. Practical aspects of conducting a pragmatic randomized trial in primary care: patient recruitment and outcome assessment. BrJ Gen Pract 2000;50:37I-4.

2. Hill CL, LaValley MP, Felson DT. Discrepancy between published report and actual conduct of randomized clinical trials. J Clin Epidemiol 2002;55:783-6.

3. Boutron I, Estellat L, Guittet L, et al. Methods of blinding in reports of randomized controlled trials assessing pharmacologic treatments: a systematic review. PLoS Med 2006;3:e425.

4. Gluud LL. Bias in clinical intervention research. Am J Epidemiol 2006;163:493501 .

5. Hrobjartsson A, Forfang E, Haahr MT, et al. Blinded trials taken to the test: an analysis of randomized clinical trials that reports tests for the success of blinding. Int J Epidemiol 2007;36:654-63. 